\title{
Comparison of some Biomotoric Properties and Anthropometric Measurements of Male Basketball and Football Players*
}

\author{
Bülent Turnal, Fatih Kılınç² \\ ${ }^{1}$ Akdeniz University, Turkey \\ ${ }^{2}$ Süleyman Demirel University, Turkey \\ Correspondence: Bülent Turna, Akdeniz University, Turkey.
}

Received: January 13, 2018

Accepted: March 28, $2018 \quad$ Online Published: April 9, 2018

doi:10.11114/jets.v6i5.2140

URL: https://doi.org/10.11114/jets.v6i5.2140

\begin{abstract}
The purpose of this study is to determine and compare some biomotoric properties and anthropometric measurements of Antalya Muratpaşa High School Boys' Basketball Team and Football Team. Thirty volunteering players from Antalya Muratpaşa High School Boys' Basketball and Football Teams participated in the study. Fifteen of the participants were from the Basketball Team and 15 were from Football Team. The mean age of the Football Team was 16,3 $\pm 0,9$ years; mean body weight was $65,6 \pm 9,4 \mathrm{~kg}$, mean height was 170,3 $\pm 6,7 \mathrm{~cm}$; and the mean age of the Basketball Team was 15,5 $\pm 0,74$ years, mean body weight was $64,8 \pm 11,7 \mathrm{~kg}$, mean height was $178,6 \pm 6,1 \mathrm{~cm}$. As well as the height, weight, age values of the 15 Basketballer and 15 Footballer Boys', the right and left grip force, back force, sprint tests, leg force, free vertical jump, subcutaneous fat measurements from 8 different points, and circumference measurements from 7 different points were taken. As a result of the comparison between some biomotoric properties, a significant difference was found between the vertical jump test values of the Basketball Team and Football Team $(p<0,05)$. When the Basketball and Football teams participating in the study were compared, it was determined that there was a statistically significant difference between the calf area sub-cutaneous fat measurement values $(p<0,05)$. No statistically significant differences were found in the measurements of shoulder, chest inspiration, chest expiration, arm, forearm, thigh circumference, calf circumference, hip circumferences of the Boys' Basketball and Football players who participated in our study $(\mathrm{p}<0,05)$. A statistically significant difference was found in the 10-m speed run tests of the Boys' Basketball Team and Football Team Players $(p<0,05)$. The data of the study were analyzed in Independent Samples T Test $(\mathrm{p}<0,05)$ according to statistical significance levels. Nobody should doubt that positive science is affecting all sports disciplines in the light of technological developments in our present age and it will continue even more in the future with more efficient and faster use to serve sports and sportsmen. In this context, it was aimed in the present study to determine how young sportsmen are suitable for their branches, and also to determine the missing and full aspects of their present biomotoric and physical statuses, supplement the missing aspects, and improve the full ones.
\end{abstract}

Keywords: biomotoric properties, anthropometry, football, basketball

\section{Introduction}

In general, developed and developing countries make young people start sports at early ages, and apply scientific training programs according to different age groups and developmental properties. It has been reported that attracting children to sports is influential in the formation of healthy and productive societies (Leblanc and Dickson, 2005). Performance is the concrete score of a sportsman in physical, biomotoric and psycho-mental terms (Kılınç, 2008).

In studies in which anthropometric properties were focused on, the issue of which body profile is suitable for which sport type is discussed. Also, the issue of which body type is important in selecting sports is investigated. The relation between development and motor performance generally depends on anthropometric factors, and contributes to the development of performance.

Today, Basketball and Football, and mostly athletics, which is considered as the ancestor of all sports, have an important place in sports concept. For this purpose, it is important to know the biomotoric and anthropometric properties of the sportsmen in these branches and to form sportsmen profiles that are specific for the branches are important issues. Anthropometric and physiological investigations contribute to the selection of the sportsmen and the training model that

\footnotetext{
*This study was partly presented at the World Congress of Sport Sciences Researches, 23-26 November 2017, Manisa
} 
will be applied to them, and to form a foresight in the targeted success (Duyul, 2005).

The purpose of this study is to determine some biomotoric and anthropometric measurements of the Muratpaşa High School Boys' Basketball Team and Football Team in Antalya, and compare the properties of the players with each other.

\section{Method}

Thirty players from Antalya, Muratpaşa High School Boys' Basketball and Football Teams participated voluntarily to the Anthropometric and biomotoric tests. Some biomotoric properties and anthropometric measurements of the players were compared with each other. The mean age of the players who basketball participated in the study was 15,5 $\pm 0,7$ years; mean height was $178,6 \pm 6,1 \mathrm{~m}$; mean body weight $64,8 \pm 11,7 \mathrm{~kg}$; and the mean age of the Footballers who participated in the study was $16,3 \pm 0,9$ years; mean height was $170,3 \pm 6,7$ m; mean body weight was $65,6 \pm 9,4 \mathrm{~kg}$. The players were not given any burdens before the day on which the measurements would be conducted and they rested. The measurements were made three hours after lunch, and after 15-min warm-up.

\section{Anthropometric Test Measurements}

The height measurements of the players were performed by making them stand in anatomic position with bare feet, and soles joints. The body weight measurements were performed with shorts and undershirt in bare feet with Baster brand scale with $0,1 \mathrm{~kg}$ sensitivity. Circumference measurements were performed in 7 different points, which were Shoulder circumference, Chest circumference (inspiration) and Chest circumference (expiration), hip circumference, thigh circumference, biceps circumference, Forearm circumference. In order to perform the subcutaneous fat measurements, Holtain brand skinfold caliper was used. The measurements were made at 8 different points, which were chest, biceps, triceps, subscapula, abdominal, subrailiac, thigh, calf. In order to determine the Body Fat Percentage values of the players, the Lange formula was made use of.

\section{Lange $=($ Biceps + triceps + Supscapula + pectoral+iliac+Quadriceps $) \times$ 0, 097+3, 64}

\section{Biomotoric Test Measurements}

Free Vertical Jump Test

Takei brand jump-meter was attached to the abdomen area of the player, the arms were let free within a certain area, and the player jumped vertically with both feet and fell within a certain area. Two trials were made and the highest value was recorded as $\mathrm{cm}$.

\section{Right-Left Hand Grip Force}

Takei Brand dynamometer was adjusted according to the size of the hands, and the player was given $45^{\circ}$ abduction position in the shoulder area, and was asked to grip with maximum force. Two trials were made and the highest value was recorded as $\mathrm{kg}$.

\section{Ten (10), Twenty (20), Thirty (30)-Meter Sprint Test}

Speed tests were made with New Test 2000 Photocell Device $50 \mathrm{~cm}$. behind the start line when the player wanted. Two trials were made and the highest value was recorded as second and split second.

\section{Data Analysis}

The data of the study were analyzed in Independent Samples T Test $(\mathrm{p}<0,05)$ according to statistical significance levels

\section{Findings}

Table 1. Comparison of Muratpaşa High School Boys’ Basketball and Football Teams Physical Values

\begin{tabular}{llllllcc}
\hline & Branch & N & Mean & Std. Deviation & T & P \\
\hline Height & Basketball & 15 & 178,63 & 6,157 & & & \\
(Cm.) & Football & 15 & 170,33 & 6,73 & & 3,554 & $\mathbf{0 , 0 0 1 *}$ \\
Kilo & Basketball & 15 & 64,86 & 11,73 & & \\
(Kg.) & Football & 15 & 65,66 & 9,43 & & & \\
Age & Basketball & 15 & 15,53 &, 74 & & 0,83 \\
(Years) & Football & 15 & 16,33 &, 97 & & & \\
\hline
\end{tabular}

$\mathrm{P}<0,05$

The mean height value was $170,3 \pm 6,7 \mathrm{~cm}$, mean body weight $65,6 \pm 9,4 \mathrm{~kg}$; mean age $16,3 \pm 0,9$ years in the Football Team; the mean height was $178,6 \pm 6,1 \mathrm{~cm}$, mean body weight $64,8 \pm 11,7 \mathrm{~kg}$, mean age $15,5 \pm 0,7$ years in the Basketball Team. As it is seen in Table 1, significant difference was detected in the age and height values in the Basketball and Football Teams, which participated in the study; and no significant difference was detected in the comparison of the weight values $(\mathrm{p}<0.05)$, which shows that Basketballers are taller than Footballers 
Table 2. Comparison of Some Biomotoric Tests of Muratpaşa High School Boys’ Basketball and Football Teams

As it may be understood in Table 2, as a result of the comparison between some biomotoric properties, a significant difference was determined in vertical jump test values of the Basketball Team and Football Team ( $\mathrm{p}<0,05)$. No significant difference was determined between leg forces, back force, right-left hand paw forces. In the light of these results it is concluded that the jumping capacities of basketballers are higher than those of the Footballers. No significant differences were detected between the back forces of Basketballers and Footballers; however, although no significant differences were detected, a small difference was detected between the back forces of Basketballers.

Table 3. Comparison of Sub-cutaneous Fat Measurements of Muratpaşa High School Boys' Basketball and Football Teams

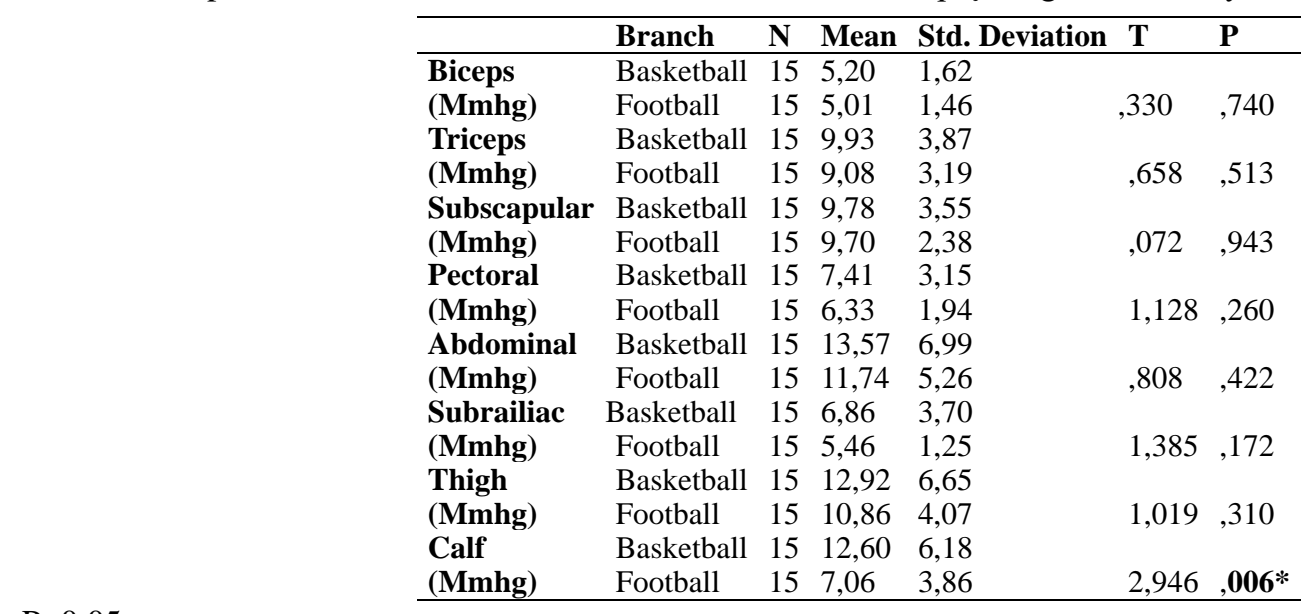

As a result of the comparison of the Basketball and Football Teams, which participated in the study, a statistically significant difference was detected between the calf area sub-cutaneous fat measurement values $(\mathrm{p}<0,05)$. No significant differences were detected in the comparisons of subcutaneous fat measurements in biceps, triceps, subscapular, pectoral, abdominal, iliac, and thigh areas. Although no statistically significant differences were detected, it was detected that the subcutaneous fat measurements of Footballers in lower extremities were less than those of Basketballer.

Table 4. Comparison of Anthropometric Circumference Measurement Values of Muratpaşa High School Boys' Basketball and Football Teams

\begin{tabular}{|c|c|c|c|c|c|c|}
\hline & Branches & $\mathbf{N}$ & Mean & Std. Deviation & $\mathbf{T}$ & $\mathbf{P}$ \\
\hline Shoulder & Basketball & 15 & 102,13 & 7,87 & & \\
\hline (Cm.) & Football & 15 & 106,03 & 7,88 & $-1,335$ & ,183 \\
\hline Chest Inspiration & Basketball & 15 & 87,63 & 6,99 & & \\
\hline (Cm.) & Football & 15 & 89,36 & 6,89 &,- 684 & ,501 \\
\hline Chest expiration & Basketball & 15 & 83,76 & 7,21 & & \\
\hline (Cm.) & Football & 15 & 85,53 & 6,88 &,- 686 & , 490 \\
\hline Arm & Basketball & 15 & 24,56 & 2,70 & & \\
\hline (Cm.) & Football & 15 & 25,10 & 2,23 &,- 588 & ,562 \\
\hline Forearm & Basketball & 15 & 23,33 & 1,94 & & \\
\hline (Cm.) & Football & 15 & 24,10 & 1,62 & $-1,172$ & ,250 \\
\hline Thigh Circumference & Basketball & 15 & 50,20 & 5,29 & & \\
\hline$(\mathbf{C m})$. & Football & 15 & 50,90 & 13,42 &,- 188 &, 855 \\
\hline Calf Circumference & Basketball & 15 & 34,96 & 3,25 & & \\
\hline$(\mathbf{C m})$. & Football & 15 & 34,10 & 2,86 & ,774 & ,444 \\
\hline Hip Circumference & Basketball & 15 & 96,90 & 6,20 & & \\
\hline (Cm.) & Football & 15 & 93,03 & 4,83 & , 416 &, 064 \\
\hline
\end{tabular}


$\mathrm{P}<0,05$

No statistically significant differences were detected in the comparison of Shoulder, Chest Inspiration, Chest expiration, Arm, Forearm, thigh circumference, calf circumference, hip circumference measurements of the Muratpaşa Boys' Basketball and Football Teams $(\mathrm{p}<0,05)$.

Table 5. Comparison of Ten (10), Twenty (20), Thirty (30)-m Speed Tests of Muratpaşa High School Boys' Basketball and Football Teams

\begin{tabular}{lllllll}
\hline & Branch & N & Mean & Std. Deviation & T & P \\
\hline Speed 10m & Basketball & 15 & 2,52 &, 17 & & \\
& Football & 15 & 2,67 &, 20 & $-2,178$ & $\mathbf{0 3 2} *$ \\
Speed 20m & Basketball & 15 & 3,85 &, 16 & & \\
& Football & 15 & 3,92 &, 20 & $-1,049$ &, 304 \\
Speed 30m & Basketball & 15 & 5,22 &, 29 & & \\
& Football & 15 & 5,14 &, 27 &, 739 &, 465 \\
\hline
\end{tabular}

$\mathrm{P}<0,05$

As a result of the study, a statistically significant difference was detected in the 10-m Speed tests of the Muratpaşa High School Basketball Team and Football Team $(\mathrm{p}<0,05)$. It was observed that the average of the Basketball Team in $10-\mathrm{m}$ Speed test was better than the Football Team average values. No significant differences were detected in the comparison of 20-m, 30-m Speed run tests $(\mathrm{p}<0,05)$.

\section{Discussion and Result}

In previous studies, it was reported that the anthropometric properties affected the performances of footballers (Gürses and Olgun, 1984; Astrand and Rodahl, 1986). Pulur (1991) conducted a study and reported that the mean age of the Football Team was 22.45 \pm 0.38 Years and the mean age of the Basketball Team was 21.60 $\pm 0,26$ Years. Eliöz (2001) conducted another study and found the mean age of the young participants as 19,32 Years. The smallest age value was found as 18 years, and the highest was found as 20 Years. Ağaoğlu and Çebi (1998) determined the mean age value of amateur footballers as 22,79 $\pm 3,0$ Years.

The comparison was made between some biomotoric and anthropometric properties of Antalya Muratpaşa High School Basketball Team (n:15) and Football Team (n:15). In this context, the mean height of the Football Team was 170,3 $\pm 6,7$ $\mathrm{cm}$, mean body weight was $65,6 \pm 9,4 \mathrm{~kg}$; mean age was $16,3 \pm 0,9$ Years; and the mean height of the Basketball Team was $178,6 \pm 6,1 \mathrm{~cm}$; mean body weight was $64,8 \pm 11,7 \mathrm{~kg}$; mean age was $15,5 \pm 0,7$ Years.

In the literature review, it was understood that the height is an important property in basketball at elite level. A statistically significant difference was found between the mean height values of the players who participated in our study $(\mathrm{p}<0,05)$. It was detected that the Basketball Team Height mean values were more than those of the Football Team players.

It is already known that the players whose sprint properties are high can have important and efficient roles in stopping the opponent in football, access to having the ball, keeping it and going for the goal. Again, it was reported in previous studies that many situations that affect the result in football appear during or after a high-level sprint (Eniseler, 1995; Müniroğlu et al, 1999). In a study conducted previously, it was reported that the 30-m sprint performances of French professional and amateur footballers did not vary; however, 10-m times of the professional players were lower at a significant level (Bloomfield et al, 2007). In the present study, it was determined that the mean values of the Basketball Team Vertical Jump and Ten (10)-m Speed test were higher than those of the Football Team at a significant level. These results support this hypothesis. In a previously conducted study, the 30-m sprint values of elite footballers whose mean age was 16,40 Years and those of the non-elite players whose mean age was 16,40 were determined as $4,31 \pm 0,14 \mathrm{~s}$ and 4,46 $\pm 0,21 \mathrm{~s}$, respectively (Reilly et al , 2000). In our study,

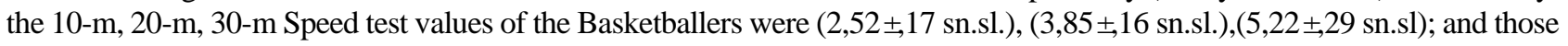

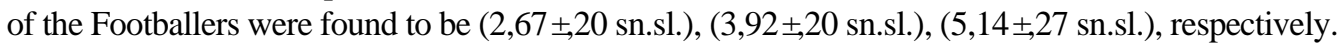

The players of Marmaris Spor Football Team, which was playing in the $3^{\text {rd }}$ League of Turkey, $(n=24)$ participated voluntarily in a previous study and the pre-test and post-test leg force values were found as 124, 35 $\pm 8,79 \mathrm{~kg} ., 138,42 \pm 10,41 \mathrm{~kg}$ (Saygin, 2001). In the present study, the leg force of the footballers was found as $100,66 \pm 30,86 \mathrm{~kg}$ and that of the Basketballers was fond as $98,83 \pm 28,85 \mathrm{~kg}$. In a study conducted with professional players, the Right Hand Grip Force was found to be $48,78 \pm 39 \mathrm{~kg}$, and the Left Hand Grip Force was found as 47,24 $\pm 3,8 \mathrm{~kg}$ (Çebi, 1999). In the present study, the Right Hand Grip Force of the Footballers was found as $36,10 \pm 7,91 \mathrm{~kg}$, and that of the Basketballers was found as $37,84 \pm 8,16 \mathrm{~kg}$. The Left Hand grip force of the Footballers was found as $34,99 \pm 7,92 \mathrm{~kg}$, and that of the Basketballers was found as $35,83 \pm 8,18 \mathrm{~kg}$.

Cerrah et al, (2011) conducted a study in 2011 with Super Amateur Footballers, and found the vertical jump values according to positions as (K: $34.7 \pm 4.5$, D: $34.6 \pm 4.4$, OS: $34.8 \pm 4.5$, F: $36.1 \pm 6.2)$ and active (K: 37.6 \pm 4.1 , D: $36.7 \pm 4.3$, OS: $37.2 \pm 5$, F: $38.8 \pm 5.2$ ). In the present study, those of the Footballers was found as $55,73 \pm 6,36 \mathrm{~cm}$, and those of the Basketballers was found as $51,06 \pm 4,46 \mathrm{~cm}$. As a result of the analyses of the data obtained in the study, a statistically significant difference was found between the Vertical Jump and Ten (10) m Speed test values, which are among some 
biomotoric properties $(\mathrm{p}<0,05)$. Although there was no statistically significant differences between the Back force, leg force, Right-Left Hand paw Force, Twenty (20) m, thirty (30) m Speed run test values, a small difference was determined between the back force of the Basketballers.

In anthropometric circumference measurements, no statistically significant difference was determined between the teams. As a result of the comparisons among the subcutaneous fat measurements, a statistically significant difference was determined in the Football Team calf area measurements when compared with the Basketballers $(p<0,05)$. Generally, the biceps, triceps, subscapula, subrailiac, thigh subcutaneous fat measurement values of the Football Team was determined to be lower than those of the Basketballers.

It was reported in previous studies that the anthropometric properties affect the performances especially of footballers. Performing the anthropometric measurements of the teams will ensure that the current statuses of the players are observed in a concrete manner, and the training plans are prepared in an efficient and productive manner

\section{References}

Ağaoğlu, S. A., \& Çebi, M. (1998). Comparison of Anthropometric and Physiological Characteristics of Amateur Footballers with Professional Footballers Hacettepe University Sports Sciences Technology High-School, 5th International Sports Science Congress, Ankara

Astrand, P. O., \& Rodahl, K. (1986). Textbook of work Physiology. Mc Graw- Hill Book Company, New York, 327-434.

Bloomfield, J., Polman, R. C. J., \& Donodhue, P. G. (2007). Physical de mands of different positions in fa premier league soccer. Journal of Sports Science and Medicine, 6, 63-70.

Çebi, M. (1999). Comparison of physiological parameters to amateur and professional football, Master's Thesis, 19 Mayis University, Institute of Health Sciences, Samsun

Cerrah, A., Polat, C., \& Ertan, H. (2011). Investigation of Some Physical and Technical Parameters According to the Situations of Super Amateur Football Players, Nigde University Journal of Physical Education And Sport Sciences $5(1)$, Niğde

Duyul, M. (2005). Comparison of Successful Effects of Some Motoric and Anthropometric Characteristics of Handball, Volleyball and Soccer University Teams (Master Thesis), 19 Mayıs University, Institute of Health Sciences, Samsun.

Eliöz, M. (2001). Comparison of Repeat Sprint Test, Fatigue and Recovery Levels in Amateur Football and Control Group, 19 Mayıs University, Institute of Health Sciences, Master Thesis, Samsun

Eniseler, N. (1995). View of speed in the football, Football Science and Technology Review, 1, 3-5.

Gürses, Ç., \& Olgun, P. (1984). Relationships between Physical Fitness and somatotype in Turkish National Athletes. Turkish Sport Foundation: İstanbul.

Kılınç, F. (2008). An Intensıve combined training program modulates Physical, physiological, biomotoric and technical parameters in basketball player women. Journal of Strength and Conditioning Research, 22(6). https://doi.org/10.1519/JSC.0b013e3181854bca

Leblanc, J., Dickson, L., Children \& Sports, Translated by Erben D., Review: Gül G., Bağırgan Publishing House, Ankara, 2005.

Müniroğlu, S., Atıl, M., Erongun, D., \& Maranc1, B. (1999). Examination of the Effects of Soccer Teams on Successful Physical Characteristics. Football Science and Technology Review, 2, 21-25.

Pulur, A. (1991). Some Physiological and Conditional Values of Top Basketball Players, Master Thesis, Ankara University, Faculty of Education, Department of Physical Education and Sports, Ankara

Reilly, T., Williams, A. M., Nevill, A., \& Franks, A. (2000). A multidisciplinary Approach to Talent İdentification in Soccer. Journal of Sports Sciences, 18, 695-702. https://doi.org/10.1080/02640410050120078

Saygin, Ö. (2001). Effect of Preparatory Training Programs on Some Physical and Physiological Characteristics of Professional Footballers, Ataturk University, School of Physical Education and Sports, Journal of the Physical Education and Sports Science, 14, 340-342.

\section{Copyrights}

Copyright for this article is retained by the author(s), with first publication rights granted to the journal.

This is an open-access article distributed under the terms and conditions of the Creative Commons Attribution license which permits unrestricted use, distribution, and reproduction in any medium, provided the original work is properly cited. 